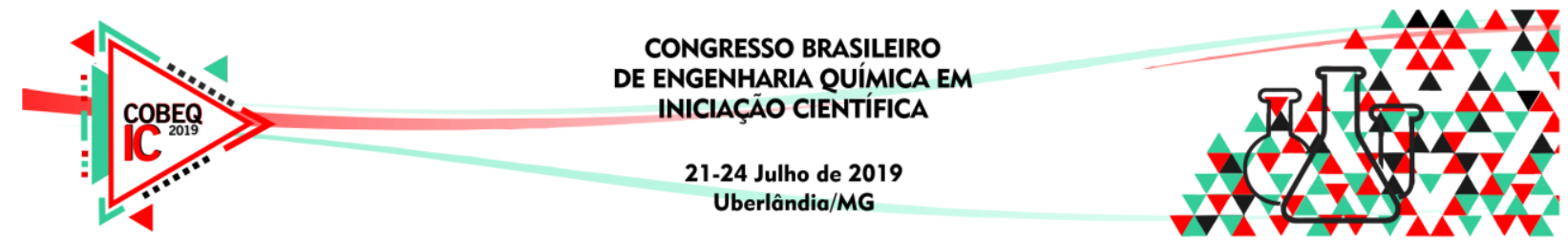

\title{
PRODUÇÃO DE BIODIESEL A PARTIR DE ÓLEO RESIDUAL PRÉ-TRATADO PELO PROCESSO DE ADSORÇÃO
}

\author{
R. L. VASCONCELOS ${ }^{1}$, L. F. MARTINS ${ }^{1}$ e S. C. DANTAS ${ }^{1}$ \\ ${ }^{1}$ Universidade Federal do Triângulo Mineiro, Instituto de Ciências Tecnológicas e Exatas, \\ Departamento de Engenharia Química \\ E-mail para contato: sandra.dantas@uftm.edu.br
}

\begin{abstract}
RESUMO - Com o desenvolvimento tecnológico a demanda de energia torna-se cada vez maior a preocupação ambiental quanto aos gases lançados na atmosfera. Estuda-se a utilização do biodiesel em substituição ao diesel, uma vez que pode ser produzido por matérias primas renováveis, tal como o óleo residual. Um dos principais fatores que afetam a produção de biodiesel por meio de óleo residual é a acidez. Este trabalho teve como principal objetivo avaliar o impacto da redução de acidez do óleo residual por meio do processo de adsorção com sabugo de milho e casca de banana na produção de biodiesel, quando comparado à produção por óleo de soja virgem e óleo residual sem este pré-tratamento. O óleo residual foi coletado pelo programa de descarte de óleos da Universidade Federal do Triangulo Mineiro. A condição do processo de adsorção foi de $20^{\circ} \mathrm{C}$ de temperatura, decorridos 35 minutos e uma concentração de $5,05 \%$ biomassa em $150 \mathrm{~mL}$ de óleo. O biodiesel foi produzido a partir da reação de transesterificação, sendo realizada pela rota metílica, catalisada por hidróxido de potássio e conduzida à temperatura ambiente, no tempo de uma hora, com proporção molar de óleo-álcool de 1:7. As quatro amostras de óleo obtiveram elevados rendimentos para produção de biodiesel, sendo o maior deles para o óleo tratado com sabugo de milho com 94,6\% seguido do óleo tratado com casca de banana com 94,0\% de rendimento. Além da análise de rendimento as amostras de biodieseis foram estudadas quanto à densidade em $26^{\circ} \mathrm{C}$, comportamento em combustão e espectroscopia por infravermelho.
\end{abstract}

\section{INTRODUÇÃO}

Devido à modernização, a preocupação com o uso dos recursos energéticos, no âmbito ambiental, se tornou realidade. O aumento da utilização de combustíveis fósseis, elevou a concentração de dióxido de carbono atmosférico em torno de 30\% (Hinrichs; Kleinch; Reis, 2012). O uso de combustíveis derivados de biomassa tem sido apontado como uma alternativa técnica capaz de minimizar problemas ambientais. Neste contexto surge o biodiesel, um biocombustível alternativo ao diesel, produzido através de óleos e gorduras. Na produção de biodiesel os óleos e gorduras animais são submetidos a uma reação química denominada transesterificação, na qual a matéria prima reage com um álcool, na presença de um catalisador e forma os alquil ésteres correspondentes da mistura de ácido graxo que é encontrado no óleo ou gordura (Knothe et al., 2006). 


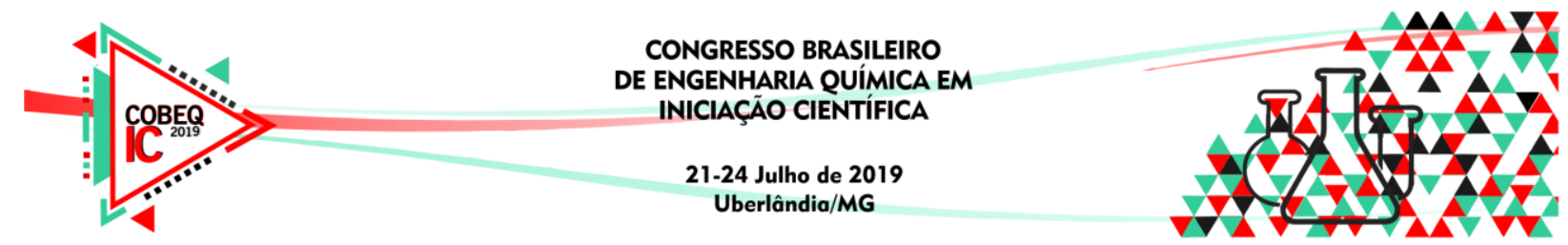

A aplicação de óleos residuais na produção de biodiesel é pertinente devido à grande quantidade de material gerado e pouca possibilidade de reutilização, tendo como destino final as redes de esgotos. O óleo residual resultante de estabelecimentos comerciais e domiciliar, possui elevado índice de acidez quando comparados aos óleos limpos, em consequência da formação de ácidos graxos livres no processo de fritura (Christoff, 2006). Sendo assim é necessário purificar o óleo residual previamente para que possa ser usado na produção de biodiesel, de modo a respeitar as normas exigidas pela Agência Nacional de Petróleo (ANP). Dentre os tratamentos possíveis, tem-se estudado o efeito do processo de adsorção no intuito de reduzir a acidez destes óleos por meio de bioadsorventes.

De acordo com este cenário, surge a motivação para o presente trabalho, que constitui no reaproveitamento do óleo residual, como matéria prima para a produção de biodiesel. Em solução ao elevado índice de acidez do óleo, o mesmo foi previamente tratado pelo processo de adsorção com casca de banana e sabugo de milho, no intuito de definir a eficiência deste processo na produção e a influência nas propriedades do produto, comparando os resultados obtidos com o biodiesel gerado por meio da reação com óleo de soja virgem e residual sem o pré tratamento.

\section{MATERIAIS E MÉTODOS}

\subsection{Teste de Adsorção}

O óleo residual foi adquirido por um projeto de extensão dos alunos da UFTM, REPOR. Com o intuito de retirar as impurezas do óleo recolhido, foi realizado um processo de filtração simples e o armazenou em frasco âmbar, mantido em lugar arejado, para evitar qualquer tipo de degradação do material. A casca de banana foi recolhida em domicílios e o sabugo de milho foi doado por uma pamonharia, situado na cidade de Uberaba. Houve um pré-tratamento dos materiais adsorventes composto pelas etapas de: remoção de sujidades; lavagem sob água corrente; secagem por estufa durante $24 \mathrm{~h}$ à $60^{\circ} \mathrm{C}$; moagem por meio de um moinho de facas do tipo Willye e por fim peneiramento para a obtenção de um material mais homogêneo com granulometria entre 1,19 e 0,250mm (16-60 mesh). Este pré-tratamento possibilitou a padronização das amostras com o objetivo de adequá-las ao processo de adsorção e melhorar a qualidade do estudo.

A condição do processo de adsorção foi baseada no estudo desenvolvido por Penholato (2016), o qual determinou a condição de otimização da adsorção de óleo residual com sabugo de milho. Sendo assim, o processo com ambas biomassas foi submetido à temperatura de $20^{\circ} \mathrm{C}$ com duração de 35 minutos e uma concentração de $5,05 \%$ biomassa, calculada conforme à densidade do óleo residual em relação à $150 \mathrm{~mL}$ de óleo. O aparato experimental utilizado para o processo de adsorção consistiu em uma unidade com tanques encamisados conectados, cada um, a um agitador mecânico. O controle de temperatura foi feito por meio de um banho termostático acoplado às células de extração.

As amostras de óleo tratado pela casca de banana e sabugo de milho, assim como o óleo de soja virgem e óleo residual foram analisadas quanto à densidade, por picnometria à $26^{\circ} \mathrm{C}$, e quanto ao índice de acidez por meio da metodologia adaptada à proposta pelas normas analíticas do Instituto Adolf Lutz (2008), sendo o titulado uma solução de éter etílico-álcool 


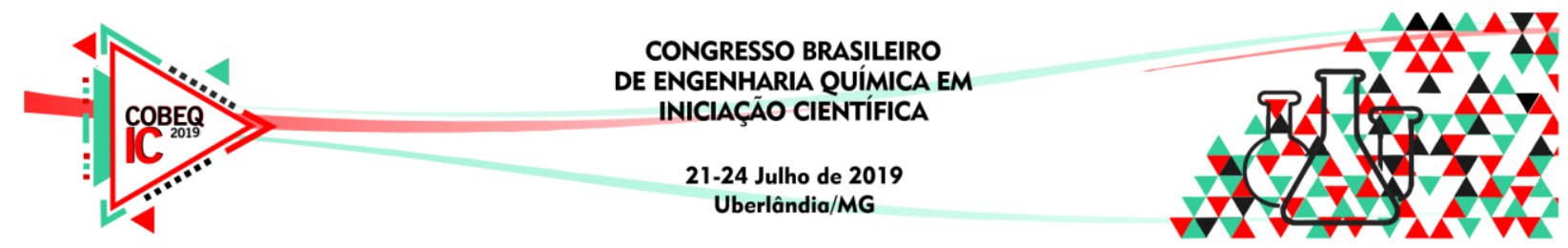

etílico (2:1) com $1 \mathrm{~g}$ do óleo em questão. $\mathrm{O}$ índice de acidez pôde ser determinado por meio da Equação 1.

$$
\text { Îndice de acidez titulável (\% ácido oleico })=\frac{V \cdot f \cdot 5,61}{P}
$$

$\mathrm{Na}$ qual, $\mathrm{V}=$ volume em $\mathrm{mL}$ da solução titulante de hidróxido de sódio necessário; $\mathrm{f}=$ fator de correção da solução titulante; $5,61=$ equivalente grama do $\mathrm{KOH} ; \mathrm{P}=$ peso da amostra de óleo em gramas.

\subsection{Produção de Biodiesel}

As condições reacionais de transesterificação foram definidas segundo a metodologia proposta por Silva (2011), através da rota metílica, catalisada por uma base $(\mathrm{KOH})$ e conduzida à temperatura ambiente, no tempo de uma hora. Solubilizou-se $2 \mathrm{~g}$ de KOH no álcool metílico, formando a solução alcoólica. A proporção molar de óleo-álcool metílico utilizada foi de 1:7. O aparato experimental, montado em capela, foi composto por béqueres de $250 \mathrm{~mL}$ sob um agitador magnético com rotação constante durante toda a reação.

Submeteu-se as quatro amostras de óleo à produção de biodiesel: ambas amostras de óleo tratadas pelos bioadsorventes, o óleo de soja virgem e óleo residual sem tratamento. Decorrido o tempo de reação, transferiu-se os produtos para o funil de separação a fim de separar as duas fases formadas durante a transesterificação (biodiesel e glicerina). Subsequentemente neutralizou-se as amostras de biodiesel com $\mathrm{HCl}$ até que se tornassem neutras e realizou-se, em todas elas, um processo consecutivo de quatro lavagens com água destilada à $70^{\circ} \mathrm{C}$, eliminando os resíduos existentes. Por fim, secou-se o biodiesel limpo em estufa por $24 \mathrm{~h}$ à $110^{\circ} \mathrm{C}$ e calculou-se o rendimento da reação por meio da Equação 2.

$$
\text { Rendimento }(\%)=\frac{\text { massa de biodiesel }}{\text { massa de bileo }} * 100
$$

Os biodieseis produzidos foram submetidos à combustão, por meio da queima de chumaços de algodão embebidos individualmente por cada uma das amostras, para analisar o comportamento da chama formada. Por fim também foram realizadas as análises de infravermelho por espectroscopia infravermelho por reflectância total atenuada em infravermelho com transformada de Fourier (ATR-FTIR). Os espectros foram obtidos na faixa de 400 a $4000 \mathrm{~cm}^{-1}$ com resolução de $4 \mathrm{~cm}^{-1}$ e 32 varreduras.

\section{ANÁLISE DE DADOS E DE RESULTADOS}

\subsection{Teste de Adsorção}

O resultado das análises de picnometria e acidez das amostras dos óleos estudados são apresentados na Tabela 1 a seguir. 


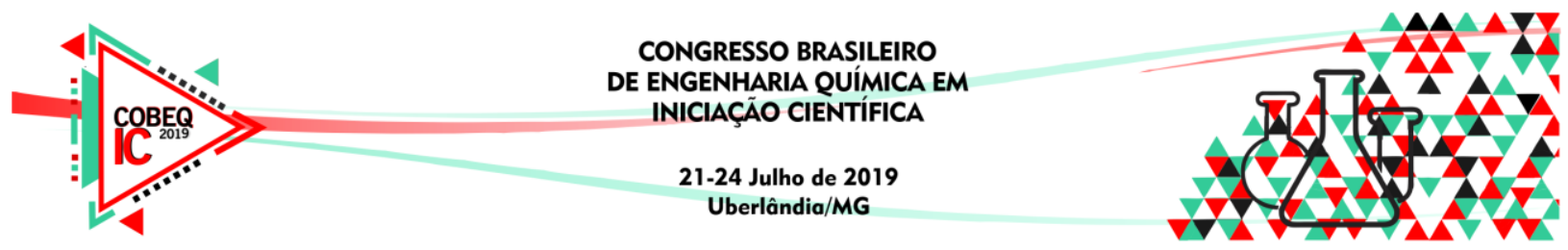

Tabela 1 - Índice de acidez e densidade dos óleos

\begin{tabular}{l|c|c}
\hline Óleo & Índice de Acidez $\left(\mathrm{mg} \mathrm{KOH} . \mathrm{g}^{-1}\right)$ & Densidade $\left(\mathrm{g} \cdot \mathrm{cm}^{-3}\right)$ \\
\hline Soja virgem & 0,437 & 0,915 \\
\hline Residual & 0,855 & 0,920 \\
\hline Tratado com sabugo de milho & 0,778 & 0,919 \\
\hline Tratado com casaca de banana & 0,739 & 0,919 \\
\hline
\end{tabular}

É nítido a diferença de acidez entre o óleo de soja virgem e o óleo residual, comprovando a formação dos ácidos graxos no processo de fritura. Nota-se que os bioadsorventes estudados reduziram a acidez do óleo residual, ou seja, diminuíram, por meio do processo de adsorção, a porcentagem de ácidos graxos livres. Porém com baixa eficiência de processo, sendo a redução de acidez com o uso do sabugo de milho em torno de $9 \%$ e para a casca de banana $13,4 \%$. Este resultado induz que a casca de banana possui potencial redutor de acidez maior que o sabugo de milho. Apenas o óleo de soja virgem está dentro dos padrões definidos pela ANP para produção de biodiesel, uma vez que é o único que possui índice de acidez menor que $0,5 \mathrm{mg} \mathrm{KOH} \cdot \mathrm{g}^{-1}$.

Quanto às densidades espera-se que a densidade do óleo residual seja maior que a do óleo virgem, em razão das impurezas presentes no óleo residual o tornarem mais denso e espesso. Este fato é observado pelos resultados obtidos pela picnometria, porém não houve redução significativa. Por meio do processo de adsorção, as densidades dos óleos tratados foram reduzidas quando comparadas ao óleo residual.

\subsection{Produção de Biodiesel}

A Figura 1 apresenta o gráfico com a porcentagem de rendimento da produção de biodiesel pelas amostras.

Figura 1 - Rendimento da produção de Biodiesel em porcentagem

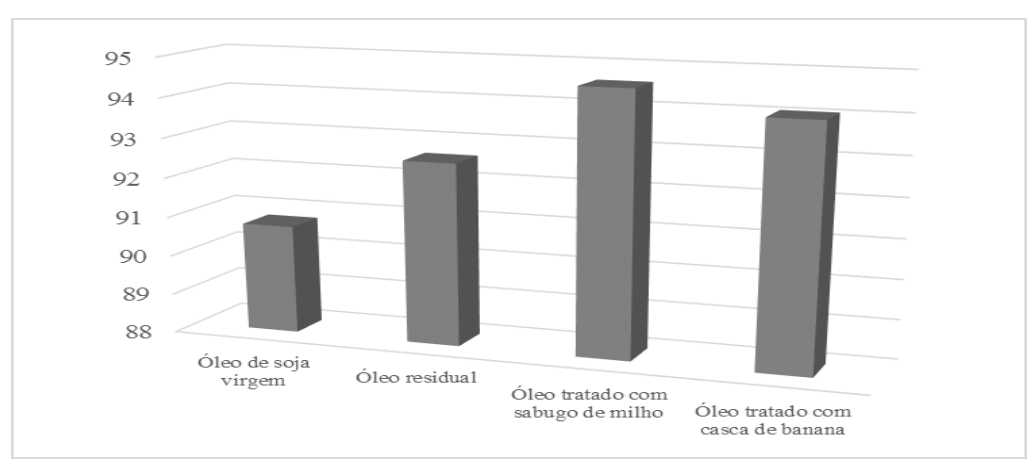

Todas as amostras apresentaram rendimento maior que 90\%. Observa-se que dentre os experimentos o óleo tratado com o sabugo de milho foi o mais eficiente na reação de transesterificação e óleo virgem foi o que obteve menor rendimento, contrariando o esperado. Porém o rendimento de aproximadamente $91 \%$ para o óleo de soja virgem mostra-se satisfatório quando comparado ao estudo desenvolvido por Félix (2017) para condições reacionais similares, obtendo um rendimento de $92,33 \%$. 


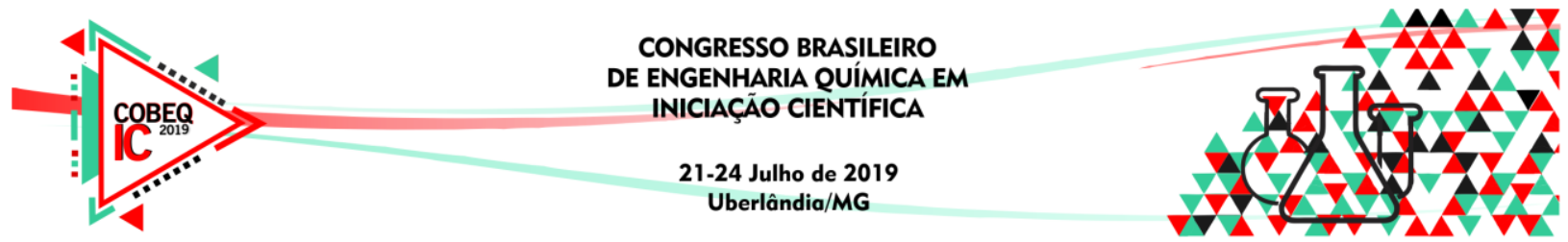

Análises de índice de acidez e densidade: A Tabela 2 dispõe dos resultados das análises de acidez e densidade das amostras.

Tabela 2 - Índice de acidez, densidade, índice de peróxido dos biodieseis

\begin{tabular}{l|c|c}
\hline Óleo & Índice de Acidez $\left(\mathrm{mg} \mathrm{KOH} \cdot \mathrm{g}^{-1}\right)$ & Densidade $\left(\mathrm{g} \cdot \mathrm{cm}^{-3}\right)$ \\
\hline Soja virgem & 1,078 & 0,880 \\
\hline Residual & 1,303 & 0,883 \\
\hline Tratado com sabugo de milho & 1,261 & 0,882 \\
\hline Tratado com casaca de banana & 1,205 & 0,882 \\
\hline
\end{tabular}

Quanto à acidez, observa-se o mesmo comportamento das amostras dos óleos de origem, porém para todas as amostras de biodiesel ocorreu um aumento do índice de acidez quando comparado aos respectivos óleos. Uma possível justificativa é a ineficiência na etapa de neutralização no processo de refino do biodiesel produzido, de modo a exceder o ácido adicionado na tentativa de neutralizar a base $\mathrm{KOH}$ utilizada na transesterificação. Analisando o resultado dos testes de picnometria nota-se que houve uma redução quanto aos valores dos óleos de origem. Na literatura a densidade encontrada para o biodiesel varia de 0,820 a $0,880 \mathrm{~g} / \mathrm{cm}^{3}$, há discrepância nos valores encontrados, porém ainda assim são aceitáveis conforme a margem de erro dos testes.

Análise de combustão: Feito o teste da chama, observou-se que todas as amostras sofreram combustão no contato com a fonte de calor, também observou-se que todas formaram chamas fortes e altas em questão de poucos minutos de queima. As amostras permaneceram com este aspecto por cerca de 15 minutos comprovando sua eficiência de combustão.

Espectroscopia Infravermelho: As respostas obtidas pelo leitor Infravermelho encontram-se agrupadas pela Figura 2 a seguir, juntamente com os dados do espectro padrão apresentado pela leitura de uma amostra de biodiesel.

Figura 2 - Espectros FTIR das amostras de biodiesel

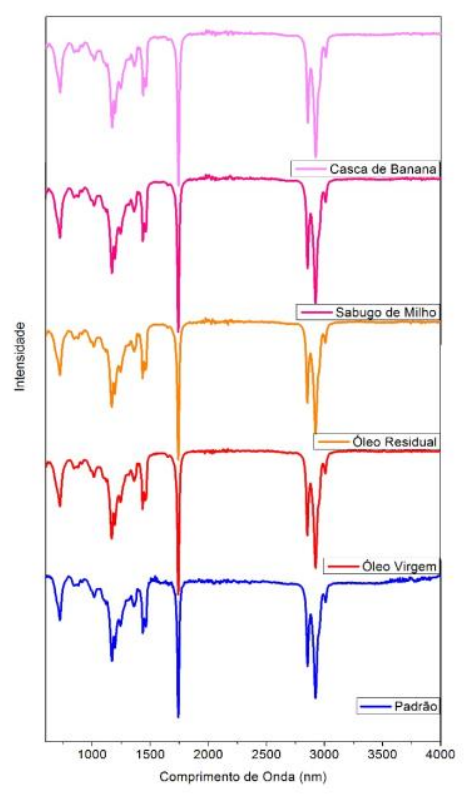




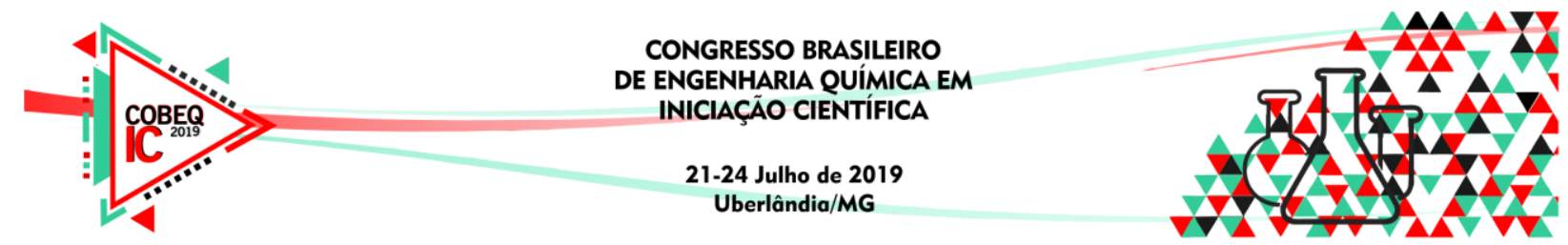

A espectroscopia no Infravermelho comprova a formação de biodiesel conforme os comprimentos de onda gerados pelas amostras, os quais se mantêm praticamente iguais à leitura do biodiesel padrão. Nota-se, em todas as amostras, a presença dos três picos característicos de ésteres nos comprimentos de onda em torno de $1250-1050 \mathrm{~cm}^{-1}$ para a ligação $\mathrm{C}-\mathrm{O} ; 1780-1650 \mathrm{~cm}^{-1}$ para a ligação $\mathrm{C}=\mathrm{O}$ e em torno de $3300-2700 \mathrm{~cm}^{-1}$ para a ligação $\mathrm{C}-\mathrm{H}$.

\section{CONSIDERAÇÕES FINAIS}

Por meio deste estudo concluiu-se inicialmente que, tanto o sabugo de milho como a casca de banana, não foram eficientes no processo de adsorção no âmbito de reduzir consideravelmente a acidez do óleo residual de cozinha, sob a condição de processo testada. Quanto a eficiência na produção de biodiesel pela transesterificação por meio da rota metílica, observa-se elevados valores, todos acima de $90 \%$. Porém os resultados são inconclusivos, em razão do óleo virgem apresentar o menor rendimento teórico, de aproximadamente $91 \%$, enquanto que os óleos tratados e óleo residual obtiveram em torno de $94 \%$ e $92 \%$, respectivamente. Com a realização da espectroscopia de infravermelho fica evidente a formação dos ésteres alquílicos, o biodiesel, em todas amostras. No teste de chama foi comprovado o potencial de combustão de todas as amostras, validando energeticamente o biodiesel produzido.

\section{REFERÊNCIAS}

CHRISTOFF, P. Produção de biodiesel a partir do óleo residual de fritura comercial. Curitiba, 2006.

FÉLIX, R.M. Estudo das condições ótimas da produção de biodiesel a partir da transesterificação do óleo de soja. Uberaba, 2015.

HINRICHS, R.A.; KLEINBACH, M.; REIS, L.B. Energia e Meio Ambiente. $4^{\mathrm{a}}$ edição. São Paulo, 2012.

INSTITUTO Adolf Lutz. Métodos físico-químicos para análise de alimentos. São Paulo,2008.

KNOTHE, G. et al. Manual de biodiesel. São Paulo: Edgar Blucher, 2006.

PENHOLATO, N.C. Redução do índice de acidez do óleo de fritura pelo processo de adsorção em sabugo de milho. Uberaba, 2016.

SILVA, T.A.R. Biodiesel de óleo residual: produção através da transesterificação por metanólise e etanólise básica, caracterização físico-química e otimização das condições reacionais. Uberlândia, 2011. 